\title{
Nucleation, Growth, Transport, and Entrapment of Inclusions During Steel Casting
}

\author{
LIFENG ZHANG ${ }^{1,2}$ \\ 1.-School of Metallurgical and Ecological Engineering, University of Science and Technology \\ Beijing, Beijing 100083, People’s Republic of China. 2.-e-mail: zhanglifeng@ustb.edu.cn
}

The nucleation, growth, transport, and entrapment of nonmetallic inclusions during the steel casting process are briefly reviewed in this article. The current main research accomplishments as well as future topics that should be focused on in this field are summarized.

\section{NONMETALLIC INCLUSIONS DURING THE STEEL REFINING AND CASTING PROCESS}

Steel produced in a basic oxygen furnace or electric furnace is tapped into a ladle for alloying and refining prior to casting. As shown in Fig. 1, the first refining step is to deoxidize the steel by adding aluminum or silicon, or other elements with a thermodynamic affinity for oxygen in the form of a ferroalloy, in an argon-stirred vessel, sometimes in vacuum. Inclusions form by elements reacting with the dissolved oxygen in the steel according to the thermodynamic stability of the elemental reactions, and their ability to nucleate. Nucleation can be homogeneous if it takes place in a pure liquid melt, or heterogeneous if there are solid particles with surface energies that favor nucleation. The inclusions grow according to collisions with other particles, precipitation from the molten steel, and other mechanisms. In the continuous casting process, the molten steel in the ladle is positioned above the tundish and the bottom slide gate is opened starting the steel flow into the tundish. Steel from the tundish exits down through a ceramic submerged entry nozzle (SEN) and enters the mold. Reoxidation is likely during nozzle transfer operations, depending on the flow relative to nozzle geometry, the presence of leaks, breaking off of partial nozzle clogs, and other factors. New inclusions, such as alumina, will nucleate and precipitate by the reaction between the absorbed oxygen from the air and the dissolved elements, such as dissolved aluminum. In the mold cavity itself, molten steel flows within the solidifying

Lifeng Zhang is the guest editor for the Process Technology and Modeling Committee of the TMS Materials Processing \& Manufacturing Division, and coordinator of the topic Modeling on the Nucleation and Growth of Particles in Metals in this issue. steel shell. The flow pattern in the mold region is controlled by the nozzle or in-gate geometry, the casting speed, the mold geometry, and argon gas injection rate. This flow pattern in turn controls the entrapment of inclusions and other defects that determine the steel quality. The flow pattern can either encourage inclusion removal, by bringing flow to the top surface slag layer, or by sending the inclusions deeper to be entrapped in the solidification front. ${ }^{1-5}$

Inclusion-related phenomena in the continuous casting mold region are shown in Fig. 2, and the inclusion-related phenomena are summarized in Table I. The current project is to quantify the contribution of these phenomena on inclusions in final products using models combining the macroscale fluid flow models and nano- and microscale inclusion models.

Inclusions in molten steel control its "cleanliness" and cause many different quality problems. Steel cleanliness depends not only on the number of inclusions but also on their morphology and size distribution. The inclusion size distribution is particularly important because large macro-inclusions are the most harmful to mechanical properties. Large inclusions, including clusters, cause the most damage. Too many smaller inclusions are detrimental as well, particularly discrete spinels or nitride inclusions in high-alloy steels. Tough, hard inclusions are more damaging than soft or brittle ones that can deform or break up during subsequent working operations. Entrapped inclusions lead to internal cracks, slivers, and blisters in the final rolled product. ${ }^{6}$ For example, the "pencil pipe"7 is caused when small argon gas bubbles surrounded by inclusions are caught in the solidifying shell. During rolling, the inclusion clusters elongate to 


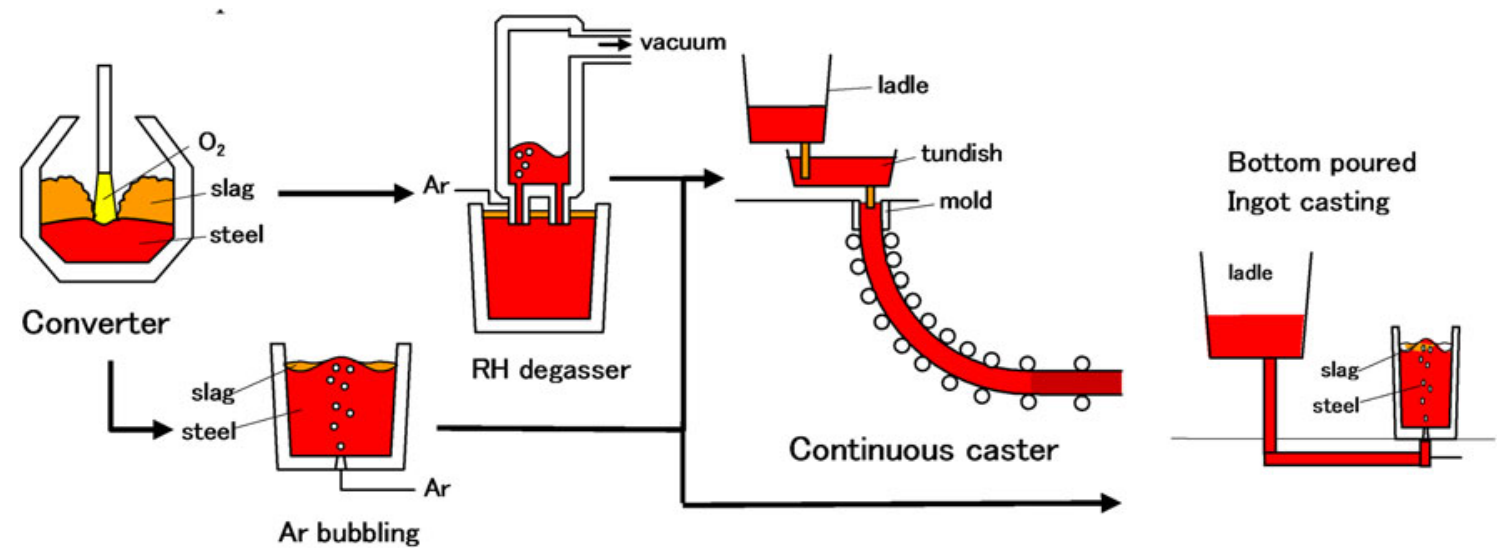

Fig. 1. Steelmaking, refining, and casting process.

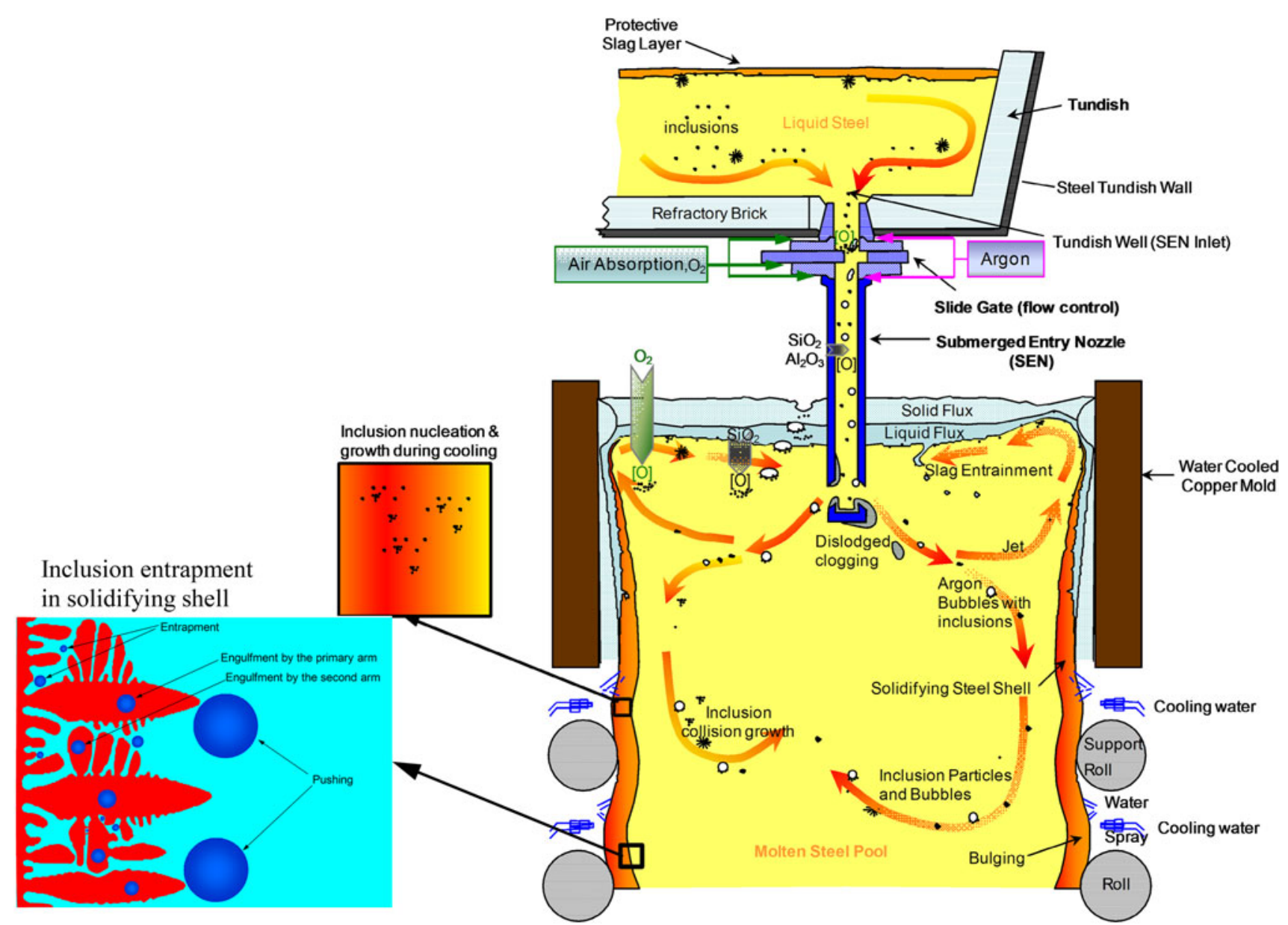

Fig. 2. Phenomena in steel continuous casting tundish and strand.

create long slivers in the final product. These intermittent defects are particularly costly because they are often not detected until after painting the finished part. Thus, there is great incentive to understand how inclusions arise, and to control the flow pattern in each vessel in order to minimize particle entrapment and the associated quality problems. Methods to minimize inclusions depend on their source. These methods include control of the compositions of steel, slag, and refractory; control of the fluid flow pattern in each vessel; injection of gas bubbles; and minimization of exposure to air. The relative effectiveness depends on proper identification of the source, and it is still not well 
understood. Large inclusions are suspected to be easier to remove, but the effectiveness in the continuous casting mold region for a given particle size has not been well quantified. The optimal strategies to remove inclusions cannot be found until the formation and removal mechanisms can be properly quantified and compared.

\section{RELEVANT REPORTED STUDIES ON THE PHENOMENA OF INCLUSIONS}

\section{Plant Experiments}

Significant insight into inclusion entrapment has been obtained in the past through conducting trials in steel plants, collecting samples, performing metallurgical analysis, and gathering statistical data. The current author has reviewed methods to detect inclusions and operating practices to improve steel cleanliness at the ladle, tundish, and continuous caster. ${ }^{5,8-20}$ Inclusions arise from many sources, including deoxidation, reoxidation, nitride formation, slag entrapment, chemical reactions, and other exogenous sources. Clues to the mechanism of their origin can be discerned from their composition and shape in the final product. The morphology of inclusions is shown in Fig. 3. Large dendritic alumina is caused by rapid growth in an oxygen-rich environment such as caused by reoxidation (Fig. 3a) and alumina clusters grow by collisions between smaller particles (Fig. $3 b^{21}$ ) in Al-killed steels. Bubbles can become entrapped in the solidified steel and are often covered with attached inclusions (Fig. $3 \mathrm{c}^{22}$ ). Solid inclusions can agglomerate on any surface with favorable surface tension effects, including refractory walls. ${ }^{22}$ Clogs forming on the surface of the nozzle wall can change the flow pattern or dislodge, ${ }^{22}$ causing defects such as TiN clusters in continuous cast Ti-stabilized stainless steel (Fig. $3 \mathrm{~d}^{23}$ ). Large spheres of complex oxides form when surface slag is entrained, and remains liquid while the steel solidifies (Fig. $3 \mathrm{e}^{21}$ ). Finally, large irregular exogenous inclusions arise from broken refractory dislodged from the vessel or nozzle walls (Fig. $3 \mathrm{f}^{21}$ ). As inclusion content steadily decreases, the cost of improvements obtained by detecting inclusions through measurements is becoming prohibitive. With so many variables to consider, industrial trails can no longer afford this approach.

\section{Macroscale Flow Pattern and Inclusion Transport $\left(10^{-3}-10^{+1} \mathrm{~m}\right)$}

Understanding of the fundamental flow in the vessel is a critical step in understanding inclusion entrapment because inclusion removal is controlled mainly by transport through the liquid flow field. Previous research, including that of the current author, has developed computational models to predict transient fluid flow behavior in various metallurgical vessels, including turbulent, three-dimensional flow 

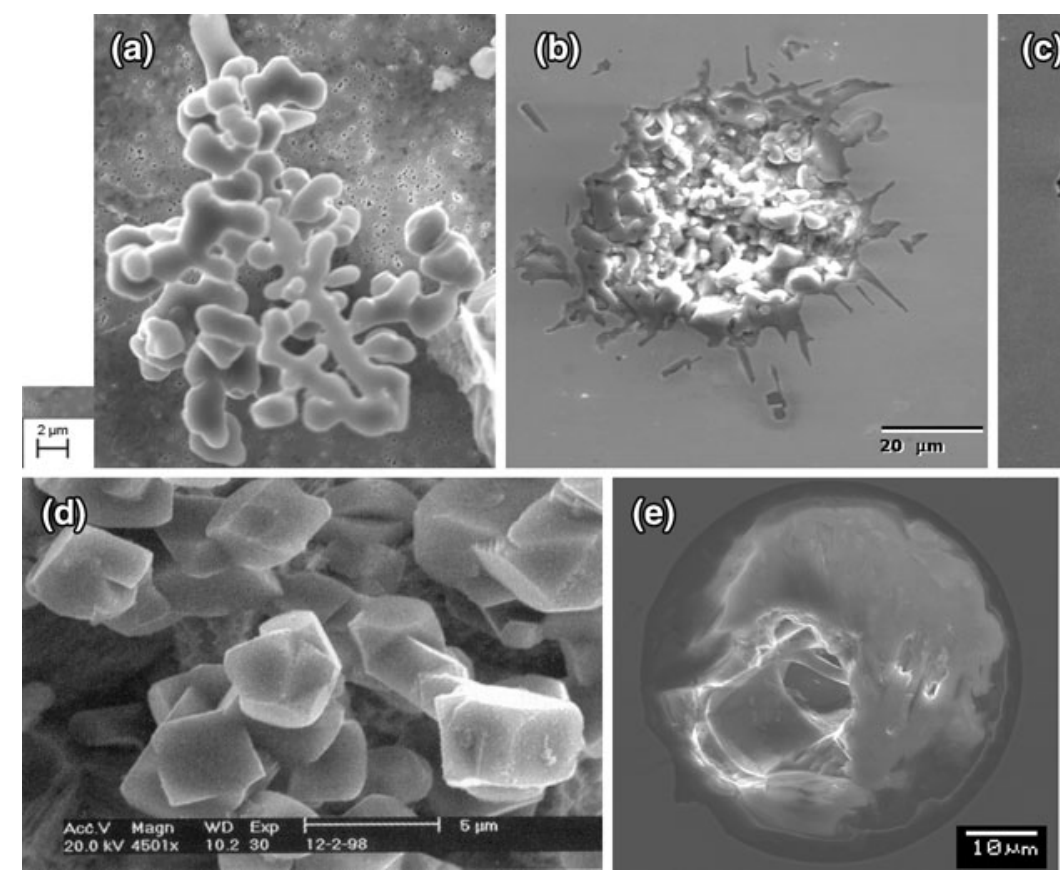

Fig. 3. Morphologies of typical inclusions: (a) dendritic alumina, (b) alumina clusters, ${ }^{21}$ (c) bubble with attached inclusions, ${ }^{24}$ (d) TiN inclusions at SEN $\operatorname{clog}^{23}$ (e) silicate inclusion, ${ }^{22}$ and (f) irregular exogenous inclusions. ${ }^{21}$

in the ladle, ${ }^{14,25,26}$ tundish, ${ }^{27-39}$ and continuouscasting mold. ${ }^{11,24,28,30,34,35,39-52}$ Some of these macroscale models have been augmented to predict the transport and removal of inclusions within the macroscopic fluid. Although encouraging, these previous modeling studies need further validation and extension to incorporate recent fundamental models of inclusion behavior on the nano- and microscales, which are discussed next.

\section{Nano- and Microscale Inclusion Phenomena $\left(10^{-9}-10^{-3} \mathrm{~m}\right)$}

Many very important phenomena governing inclusion behavior occur at very small size and time scales and occur within interfacial regions that measure only a few atoms in thickness. The formation and growth of inclusions in steel was studied extensively 2540 years ago by different researchers, such as Elliott and coworkers, ${ }^{53,54}$ Flemings and co-workers, ${ }^{54}$ Turkdogan, ${ }^{55,56}$ Olette and coworkers, ${ }^{57-59}$ Fruehan and coworkers, ${ }^{60}$ Szekely and coworkers, ${ }^{61-64}$ Cramb and coworkers, ${ }^{65-68}$ Thomas and coworkers, ${ }^{69,70}$ and Zhang. ${ }^{3,4,24,25,27,71-73}$ As shown in Fig. 4, ${ }^{74}$ nucleation occurs at nanoscales in both time and length and is governed by diffusion of the deoxidization elements and oxygen, ${ }^{71,72,75,76}$ Brownian collision, 27,72,75,76 and Ostwald ripening. ${ }^{72,75-79}$ Particle growth occurs at microscales depending on the microscale phenomena of bubble attachment, turbulent collisions, ${ }^{27,72,75,76}$ interface reactions, reoxidation, and local thermodynamics. ${ }^{20,80-83}$ Finally, inclusion transport and removal at the slag or by bubble flotation $24,26,84,85$ and particle entrapment in solidifying dendritic interfaces $^{3-5,73}$ depend on flow transport and on the nature of the flow pattern and shape of the metallurgical vessel. Different nano- and microscale models have been used to predict important specific phenomena. The current author considered bubble flotation as one of several inclusion removal methods, and he computed the attachment probability of inclusions to bubbles and matched water model experiments, showing that this probability depends on bubble size, particle size, turbulent dissipation, and gas flow rate. $24,51,84-87$

\section{FUTURE FOCUS ON THE STUDIES OF THE NUCLEATION, GROWTH, TRANSPORT, AND ENTRAPMENT OF INCLUSIONS IN STEEL}

The summarized work in this article has enabled the development of improved modeling tools and has led to improved fundamental insights into the process. However, this previous work also has the following disadvantages:

- The nano- and microscopic nucleation and growth of inclusions were not really coupled with the local macroscopic fluid flow, and the evolution of size distribution was rarely investigated. The models for the nucleation and growth of inclusions were mostly analytically but not numerically solved.

- It was difficult to apply the previous models to industrial practice because the complex fundamental relationships among the macroscale flow pattern, the nano- and microscale inclusion phenomena, and the relative importance of different mechanisms for inclusion formation and entrapment have not yet been quantified. 


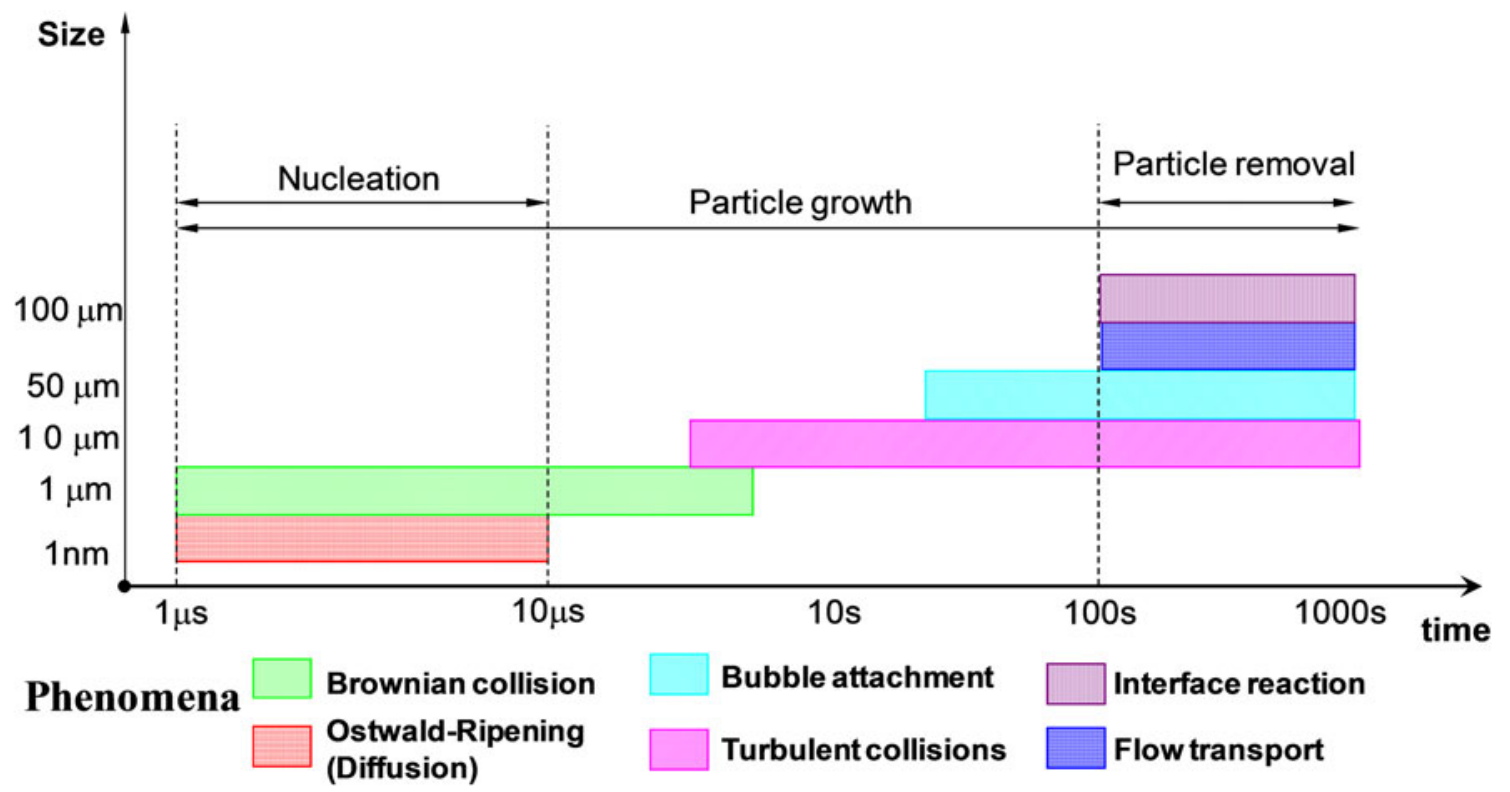

Fig. 4. Scale and control mechanisms during inclusion nucleation, growth, and removal. ${ }^{74}$

- The computational models have been developed for specific processes, or for specific phenomena, but to date have never included enough of the phenomena and processes together to be useful in overall process design and control.The future work on the nucleation and growth of inclusions should include the following innovative items:

- Combining the nano- and microscale phenomena (inclusion nucleation and growth, and the entrapment of inclusions to the solidifying shell, slag, and bubble surface) with macroscale fluid flow in the molten steel.

- Numerically but not analytically solving the nucleation, collision, and growth of inclusions with pseudo-molecules as starting points.

- Predicting the composition, quantity, and size distribution evolution of inclusions during steel casting processes, and predicting the final distribution location of inclusions in casting products.

- Considering the newly generated inclusions from air absorption, the reaction between molten steel and slag and lining refractory, and from the precipitation during cooling process.

- Applying the proposed model to optimize the refining and casting operation to improve the removal of inclusions and achieve the high clean steel.Having developed models to capture the microscale phenomena important to inclusion behavior, the next step is to incorporate them into the macroscale fluid flow models. This model will be incorporated into the macroflow model. By accurately adding size groups that feature continuous doubling of size, this model can span the complete range of inclusion sizes encountered and track size distribution evolution within a macroscale flow model without becoming computationally prohibitive. The local pseudo-molecule concentration and the inclusion size distribution will be used as state variables to communicate between the model scales.

The methodology to combine the nano- and microscale inclusion models with the macroscale fluid flow models is schematically shown in Fig. 5. After the calculation of macroscale 3D fluid flow, the trajectory of bubbles and inclusions will be calculated by solving Lagrangian transport equations as a postprocessing step. The attachment probability of inclusions to bubbles will be calculated through the trajectory calculation. Then the macroscale 3D concentration of inclusions with different sizes will be calculated, nano- and microscale nucleation and growth models of inclusions will be reviewed, and the microscale bubble-inclusion interaction will be added into the inclusion concentration as a source term. Every size of inclusions will have a concentration field. The microscale attachment model of inclusions to the solidifying shell, to the SEN lining, and to the slag layer will be the boundary conditions for the inclusion concentration calculation and inclusion trajectory calculation.

The concentration equation of inclusions with different sizes in the flow is

$$
\frac{\partial}{\partial t}\left(N_{j}\right)+\frac{\partial}{\partial x_{i}}\left[\left(u_{i}+V_{T, i}\right) N_{j}\right]-\frac{\partial}{\partial x_{i}}\left(D_{\text {eff }} \frac{\partial N_{j}}{\partial x_{i}}\right)=S_{j}
$$

where $N_{j}$ is $i, V_{\mathrm{T}}$ is the terminal rising velocity of inclusions, and $D_{\text {eff }}$ is the effective diffusion coefficient. The source term at the right-hand side include the growth of inclusions by diffusion, Brownian collision, and turbulent collision. 


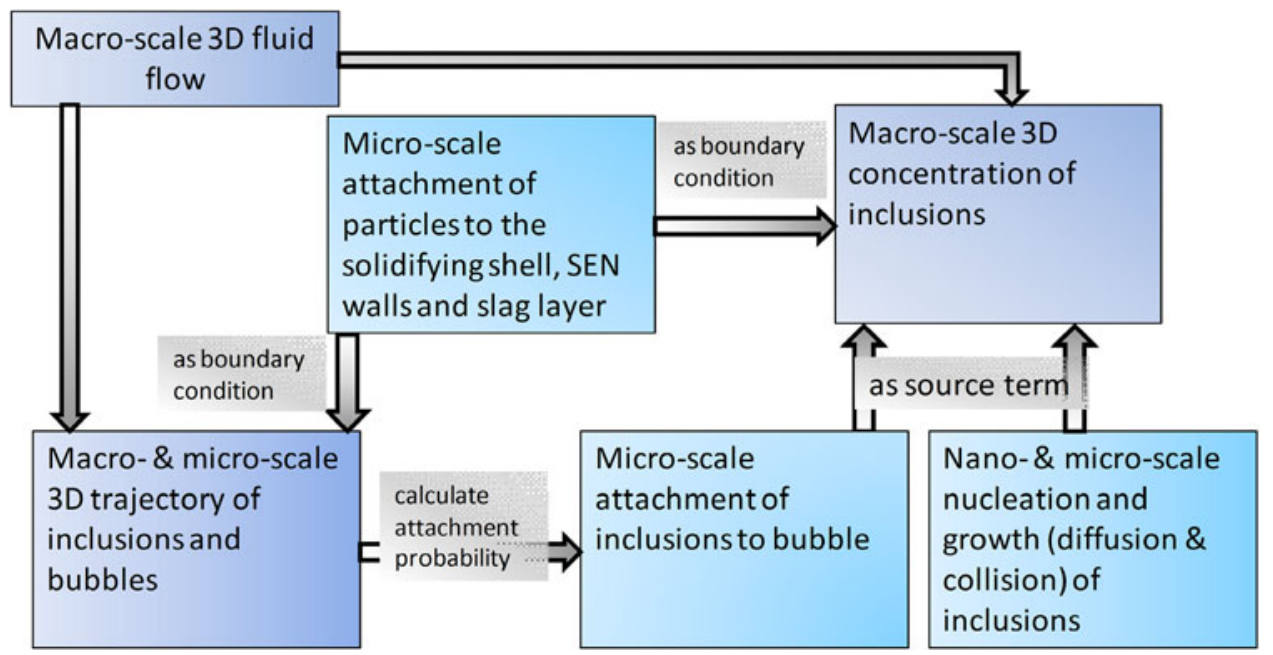

Fig. 5. Methodology to combine the nano- and microscale inclusion models with the macroscale fluid flow models.

\section{THE CURRENT JOM TOPIC}

The current JOM topic concerns the modeling of the nucleation and growth of particles in metals. This topic focuses on the nucleation, growth (by diffusion, collision, etc.), motion, and removal of second-phase particles in metals, such as the nonmetallic inclusions in metals, the precipitates in metals during cooling, solidification and heat treatment, and bubbles in metals. Four articles were collected for this topic. B. Rheingans and E.J. Mittemeijer proposed a generalized modular model for phase transformation kinetics and investigated the crystallization of a Fe-Ni-B metallic glass, the allotropic hcp-fcc transformation in cobalt, and the precipitation kinetics in a supersaturated $\mathrm{CuCo}$ alloy. H. Ling and L. Zhang studied the growth and removal of nonmetallic inclusion particles in a steel continuous casting tundish using mathematical modeling. J.P. Bellot et al. studied the growth of inclusions by diffusion and collision in metals using numerical modeling and focused on inclusions in the Ti VAR remelting process, TiN inclusions in the melt of a maraging steel, and inclusions in the liquid steel of a gas-stirred ladle. W. Yang et al. performed thermodynamic calculation on the nucleation of alumina inclusions in steel and observed the aggregate morphology of alumina inclusions in steel.

\section{ACKNOWLEDGEMENTS}

The author is grateful for support from the National Science Foundation China (Grant No. 51274034), the Laboratory of Green Process Metallurgy and Modeling $\left(\mathrm{GPM}^{2}\right)$, and the High Quality Steel Consortium at the University of Science and Technology Beijing (China).

\section{REFERENCES}

1. Q. Yuan and B.G. Thomas, ICS 2005-The 3rd International Congress on the Science and Technology of Steelmaking (Warrendale, PA: AIST, 2005), pp. 745-759.

2. C. Pfeiler, B.G. Thomas, M. Wu, A. Ludwig, and A. Kharicha, Steel Res. Int. 79, 599 (2006).

3. L. Zhang, JOM 64, 1063 (2012).

4. L. Zhang, Y. Chen, and S. Yang, Supplemental Proceedings, Vol. 2: Materials Properties, Characterization and Modeling, TMS 2012 Annual Meeting (Warrendale, PA: The Minerals, Metals \& Materials Society; Hoboken, NJ: Wiley, 2012), pp. 169-176.

5. L. Zhang, Y. Wang, E. Martinez, and K.D. Peaslee, CFD Modeling and Simulation in Materials, ed. L. Nastac, L. Zhang, B.G. Thomas, A. Sabau, N. El-Kaddah, A.C. Powell, and H. Combeau (Warrendale, PA: The Minerals, Metals \& Materials Society; Hoboken, NJ: Wiley, 2012), pp. 3-16.

6. J. Herbertson, Q.L. He, P.J. Flint, and R.B. Mahapatra, Steelmaking Conference Proceedings, vol. 74 (Warrendale, PA: ISS, 1991), pp. 171-185.

7. W.H. Emling, T.A. Waugaman, S.L. Feldbauer, and A.W. Cramb, Steelmaking Conference Proceedings, vol. 77 (Warrendale, PA: ISS, 1991), pp. 371-379.

8. L. Zhang and B.G. Thomas, ISIJ Int. 43, 271 (2003).

9. L. Zhang, J. Zhi, F. Mei, L. Zhu, X. Jiang, J. Shen, J. Cui, K. Cai, and B.G. Thomas, Ironmak. Steelmak. 33, 129 (2006).

10. L. Zhang and S. Liu, METEC InSteelCon2007: 3rd International Conference on New Developments in Metallurgical Process Technologies (Düsseldorf, Germany, 2007), pp. 642-649.

11. L. Zhang, S. Yang, K. Cai, J. Li, X. Wan, and B.G. Thomas, Metall. Mater. Trans. B 38B, 63 (2007).

12. L. Sun, L. Zhang, J. Li, A. Dong, Y. Chen, and S. Yang, Iron Steel Technol. 9, 20 (2012).

13. W. Yang, X. Wang, L. Zhang, Q. Shan, and X. Liu, Steel Res. Int. 84, 473 (2013).

14. S. Yang, L. Zhang, J. Li, K. Peaslee, H. Tang, and D. Wen, AISTech 2009-The Iron \& Steel Technology Conference, vol. I (Warrandale, PA: AIST, 2009), pp. 907-915.

15. W. Yang, L. Zhang, X. Wang, Y. Ren, X. Liu, and Q. Shan, ISIJ Int. 53 (2013), in press.

16. W. Yang, X. Wang, L. Zhang, and W. Wang, Steel Res. Int. 84 (2013), in press.

17. Y. Ren, L. Zhang, S. Yang, and W. Yang, AISTech 2013 Proceedings (Warrendale, PA: AIST, 2013), pp. 1159-1166.

18. K. Bevans, M. Chott, S.M.B. Ensor, J. Fitzgerald, K. Peaslee, S. Pisarik, L. Walker, M. Wilson, and L. Zhang, Iron Steel Technol. 10, 266 (2013). 
19. L. Zhang, Y. Chen, and S. Yang, EPD Congress 2012, ed. L. Zhang, J.A. Pomykala, and A. Ciftja (Warrendale, PA: The Minerals, Metals \& Materials Society; Hoboken, NJ: Wiley, 2012), pp. 51-61.

20. S. Yang, L. Zhang, J. Li, and K. Peaslee, Metall. Mater. Trans. B 43B, 731 (2012).

21. L. Zhang, B.G. Thomas, and B. Rietow, Report No. CCC200406, University of Illinois at Urbana-Champaign, 2004.

22. L. Zhang, B. Rietow, K. Eakin, and B.G. Thomas, ISIJ Int. 46, 670 (2006)

23. R. Maddalena, R. Rastogi, S. Bassem, and A.W. Cramb, Ironmak. Steelmak. 27, 71 (2000).

24. L. Zhang, J. Aoki, and B.G. Thomas, Metall. Mater. Trans. B 37B, 361 (2006).

25. J. Aoki, L. Zhang, and B.G. Thomas, ICS 2005-The 3rd International Congress on the Science and Technology of Steelmaking (Warrandale, PA: AIST, 2005), pp. 319-322.

26. L. Zhang and S. Taniguchi, Materials Processing in the Computer Age III, ed. V.R. Voller and H. Henein (Warrendale, PA: TMS, 2000), pp. 111-122.

27. L. Zhang, S. Taniguchi, and K. Cai, Metall. Mater. Trans. B 31B, 253 (2000).

28. G. Wen, L. Zhang, P. Tang, Z. Su, M. Zhu, W. Gu, K. Zhao, and G. Song, ISSTech2003 (Warrandale, PA: ISS, 2003), pp. 577-588.

29. L. Zhang, Y. Wang, D. Zhou, X. Hu, and K. Qian, Proceedings of the Third International Conference on Continuous Casting of Steel in Developing Countries (CCC'04) (Beijing, China: CSM, 2004), pp. 641-646.

30. M. Zhu, G. Wen, L. Zhang, P. Tang, Z. Su, W. Gu, K. Zhao, and G. Song, Proceedings of the Third International Conference on Continuous Casting of Steel in Developing Countries (CCC'04) (Beijing, China: CSM, 2004), pp. 214-220.

31. L. Zhang, J. Univ. Sci. Technol. Beijing 12, 116 (2005) (English Edition).

32. L. Zhang, J. Iron. Steel Res. Int. 12, 20 (2005).

33. L. Zhang, J. Iron. Steel Res. Int. 12, 13 (2005).

34. L. Zhang, Steel Res. Int. 76, 784 (2005).

35. L. Zhang, Fifth International Conference on Computational Fluid Dynamics in the Process Industries (CFD2006): CD Proceedings (Melbourne, Australia, 2006).

36. S. Yang, L. Zhang, K. Peaslee, J. Li, S. Shi, and Z. Zuo, ISIJ Int. 49, 1551 (2009).

37. L. Zhang, Proceedings of AISTech 2009 Iron \& Steel Technology Conference and Exposition, vol. II (Warrandale, PA: AIST, 2009), pp. 603-610.

38. L. Zhang, Iron Steel Technol. 7, 55 (2010).

39. S. Yang, L. Zhang, J. Li, and K.D. Peaslee, Proceedings of AISTech 2011 Iron \& Steel Technology Conference and Exposition, vol. II (Warrandale, PA: AIST, 2011), pp. 717-729.

40. B.G. Thomas, L. Zhang, and T. Shi, Report No. CCC200105, University of Illinois at Urbana-Champaign, 2001.

41. G. Wen, P. Tang, L. Zhang, Y. Liu, and S. Miao, Materials Science \& Technology 2004 (MS\&T'04), vol. 2 (Warrandale, PA: TMS \& AIST, 2004), pp. 69-73.

42. L. Zhang and B.G. Thomas, Report No. CCC200402, University of Illinois at Urbana-Champaign, 2004.

43. L. Zhang, S. Yang, X. Wang, K. Cai, J. Li, X. Wan, and B.G. Thomas, AISTech2004 (Warrandale, PA: ISS, 2004), pp. 879-894.

44. Y. Wang and L. Zhang, Clean Steel 161 (2007).

45. L. Zhang, Y. Wang, and X. Zuo, Metall. Mater. Trans. B 39B, 534 (2008).

46. Y. Chen, L. Zhang, S. Yang, and J. Li, JOM 64, 1080 (2012).

47. Q. Wang, S. Li, Y. Li, L. Zhang, and X. Wang, TMS 2013 Annual Meeting (Warrendale, PA: TMS, 2013), pp. 135-142.

48. L. Zhang and B.G. Thomas, XXIV Steelmaking National Symposium Mexico (Morelia, Mich, Mexico, 2003), pp. 184-198.

49. X. Wang and L. Zhang, Proccedings of AISTech 2006 Iron \& Steel Technology Conference and Exposition, Vol. II (Warrandale, PA: AIST, 2006), pp. 371-379.

50. L. Zhang and B.G. Thomas, J. Univ. Sci. Technol. Beijing 13, 293 (2006).
51. Y. Wang, A. Dong, and L. Zhang, Steel Res. Int. 82, 428 (2011).

52. Y. Wang and L. Zhang, Metall. Mater. Trans. B 42B, 1319 (2011).

53. M.L. Turpin and J.F. Elliott, J. Iron Steel Inst. 204, 217 (1966).

54. T.B. Braun, J.F. Elliott, and M.C. Flemings, Metall. Trans. $B$ 10B, 171 (1979).

55. E.T. Turkdogan, J. Iron Steel Inst. 204, 914 (1966).

56. E.T. Turkdogan, J. Iron Steel Inst. 210, 21 (1972).

57. P. Kazakevitch and M. Olette, International Conference on Production and Application of Clean Steels (London, U.K.: The Iron and Steel Institute, 1970), pp. 42-49.

58. M. Olette and C. Gatellier, Information Symposium of Casting and Solidification of Steel, vol. 1, ed. J.M. Gibb (Guildford: IPC Science and Technology Press Ltd, 1977), pp. $1-60$.

59. M. Olette and C. Catellier, 2nd International Conference on Clean Steel (London, U.K.: Metal Society, 1983), pp. 165185.

60. K. Larsen and R.J. Fruehan, Iron Steelmak. 12, 125 (1991),

61. S. Asai and J. Szekely, Ironmak. Steelmak. 3, 205 (1975).

62. K. Nakanishi and J. Szekely, Trans. ISIJ 15, 522 (1975).

63. K. Nakanishi, J. Szekely, T. Fujii, Y. Mihara, and S. Iwaoka, Metall. Trans. B 6B, 111 (1975).

64. A.G. Szekely, Metall. Trans. B 7B, 259 (1976).

65. M. Byrne, T.W. Fenicle, and A.W. Cramb, Steelmaking Conference Proceedings, vol. 68 (Warrendale, PA: ISS, 1985), pp. 451-461, 999.

66. A.W. Cramb, Inclusion Formation During Foundry Processing, http://neon.mems.cmu.edu/afs/afs2/window2.html. Accessed 1996.

67. A.W. Cramb, Impurities in Engineered Materials: Impact, Reliability and Control, ed. C.L. Briant (New York: Marcel Dekker Inc., 1999), pp. 49-89.

68. R. Rastogi and A.W. Cramb, Steelmaking Conference Proceedings, Vol. 84 (Warrendale, PA: ISS, 2001), pp. 789-829.

69. Y. Miki, B.G. Thomas, A. Denissov, and Y. Shimada, Ironmak. Steelmak. 24, 31 (1997).

70. Y. Miki and B.G. Thomas, Metall. Mater. Trans. B 30B, 639 (1999).

71. L. Zhang, W. Pluschkell, and B.G. Thomas, 85th Steelmaking Conference Proceedings, Vol. 85 (Warrandale, PA: ISS 2002), pp. 463-476.

72. L. Zhang and W. Pluschkell, Ironmak. Steelmak. 30, 106 (2003).

73. L. Zhang, S. Yang, and L.N.W. Damoah, J. Iron. Steel Res. Int. 18, 283 (2011).

74. L. Zhang, Characterization of Minerals, Metals, and Materials, ed. A. Gokhale, J. Li, and T. Okabe (Warrendale, PA TMS, 2007), pp. 35-44.

75. T. Kawawa and M. Ohkubo, Trans. ISIJ 8, 203 (1968).

76. M. Suzuki, R. Yamaguchi, K. Murakami, and M. Nakada, ISIJ Int. 41, 247 (2001)

77. L. Kampmann and M. Kahlweit, Berichte der BunsenGesellschaft physikalische Chemie 71, 78 (1967).

78. L. Kampmann and M. Kahlweit, Berichte der BunsenGesellschaft physikalische Chemie 74, 456 (1970).

79. M. Kahlweit, Berichte der Bunsen-Gesellschaft physikalische Chemie 78, 997 (1974).

80. H. Suito and R. Inoue, ISIJ Int. 36, 528 (1996).

81. H. Itoh, M. Hino, and S. Ban-ya, Metall. Mater. Trans. B 28B, 953 (1997).

82. K. Wasai and K. Mukai, Metall. Mater. Trans. B 30B, 1065 (1999).

83. M. Hino, 182th-183th Nishiyama Memorial Seminar (Tokyo: ISIJ, 2004), pp. 1-26.

84. L. Zhang and S. Taniguchi, Ironmak. Steelmak. 29, 326 (2002).

85. L. Zhang and S. Taniguchi, Int. Mater. Rev. 45, 59 (2000).

86. L. Zhang and S. Taniguchi, Ironmak. Steelmak. 28, 55 (2001).

87. L. Zhang, J. Iron Steel Res. Int. 13, 1 (2006). 